Edith Cowan University

Research Online

Research outputs 2014 to 2021

2021

\title{
Communication surrounding initiation and withdrawal of non- invasive ventilation in adults with motor neuron(e) disease: Clinicians' and family members' perspectives
}

Charlotte Chapman

Edith Cowan University

Sara Bayes

Edith Cowan University

Moira Sim

Edith Cowan University

Follow this and additional works at: https://ro.ecu.edu.au/ecuworkspost2013

Part of the Medicine and Health Sciences Commons

$10.1177 / 20534345211010132$

This is an author's accepted manuscript of: Chapman, C., Bayes, S., \& Sim, M. (2021). Communication surrounding initiation and withdrawal of non-invasive ventilation in adults with motor neuron (e) disease: Clinicians' and family members' perspectives. International Journal of Care Coordination (SAGE), 24 (3-4), p. 96-106.

https://doi.org/10.1177/20534345211010132

This Journal Article is posted at Research Online.

https://ro.ecu.edu.au/ecuworkspost2013/10362 
Communication surrounding initiation and withdrawal of non-invasive ventilation in adults with Motor Neuron(e) Disease: clinicians' and family members' perspectives

Name: Dr. Charlotte Chapman

Address: 35 Gemmell Road C/O Post Office Boyanup, Western Australia

Email: lottielloyd@westnet.com.au

Institution: Edith Cowan University, Joondalup, Western Australia

Co-authors: Dr. Sara Bayes, Prof. Moira Sim

Word Count:

ORCHID: https://orcid.org/0000-0002-6672-0524 


\begin{abstract}
Introduction

International guidelines recommend that health care clinicians communicate with people with MND and their family members about non-invasive ventilation (NIV) and percutaneous gastrostomy tube (PEG) prior to or at the onset of respiratory symptoms. This study sought to discover the degree to which these recommendations are followed in
\end{abstract}

practice.

\title{
Methods
}

Interpretive Description methodology was employed for this study, which was set in two Australian states. Nineteen clinicians experienced in caring for people with MND, six relatives of recently deceased people with MND and one person with MND participated in semi-structured in-depth interviews. Clinicians' accounts of their NIV and PEG-related communications were compared to the family member participants' recollections of their own discussions with clinicians on these topics. Data were analysed thematically.

\section{Results}

Six major themes emerged from data analysis that together capture the factors that impact practitioner-patient-family communications about NIV and PEGs. Some clinicians were unaware of MND international guidelines particularly communicating the burdens or possible withdrawal of NIV or found them challenging to implement. Consequently, family participants reported that they and their relatives with MND found clinicians' communication on these topics inadequate. This led to them 'topping up' their knowledge from less authoritative sources, predominantly the internet.

\section{Discussion}

Clinicians' lack of awareness of the international guidelines and discomfort about discussing the benefits and burdens of NIV and PEGs means that health care users and their loved ones are at risk of being unprepared for the consequences of commencing, using and ceasing NIV. Further research to discover how best to implement the evidence-based guidance on this topic into practice is warranted.

Keywords: Motor Neuron(e) Disease, amyotrophic lateral sclerosis, palliative Care, noninvasive ventilation, communication

\section{Introduction}

Motor Neurone Disease (MND), the most common form being Amyotrophic Lateral Sclerosis (ALS), is a progressive neurological condition that adversely affects muscular control $^{1,2}$. Muscles weaken, causing breathing, communication and swallowing difficulties, 
and ultimately respiratory failure and death. Respiratory failure is often a complication of respiratory infection secondary to aspiration. The duration of survival from the onset of symptoms is $20-48$ months ${ }^{3}$.

The global incidence of MND / ALS was calculated in 2019 as ranging between 0.63.8 per 100000 person-years, and as proportionally higher in Europe (2.1-3.8 per 100000 person years) than in Asia (0.8-1.2 per 100000 person years) ${ }^{4}$. This represents an overall rise in recent years: in 2005 the estimate of the worldwide occurrence was $1.5-2$ per 100,000 per year ${ }^{5}$, with an approximate lifetime risk of developing the disease of 1 in $800^{6}$, and a subsequent systematic review of European literature suggested this had increased to 2.08 per 100,000 four years later ${ }^{7}$.

In June 2019 more than 2,000 people were known to have MND in Australia (60\% male and $40 \%$ female). At that time two people were diagnosed with MND and two people died from MND in Australia each day. The prevalence of MND in 2015 was 8.7 per 100,000 people or 1 per 11,434 Australians. The global increase in cases noted earlier appears to include Australia: In 2016, 791 persons died from MND in Australia compared to 592 in 2001 ${ }^{8} \mathrm{MND}$ is a progressive, terminal neurological disease for which there is no known cure and no effective treatment ${ }^{8}$.

The disease presents a number of care-related challenges, beginning with it being extremely difficult to diagnose because symptoms may be isolated and unexplained ${ }^{9}$ and compounded by the progressive loss of limb use and the ability to speak, swallow and breathe, all while the person's mind and senses usually remain intact. As respiratory muscles become progressively affected, non-invasive ventilation (NIV) is usually offered to alleviate distressing respiratory symptoms. There is general agreement that in addition to symptom relief, NIV can improve survival, particularly if there is no bulbar involvement ${ }^{9,10}$. The consideration of a feeding tube via Percutaneous Endoscopic Gastrostomy (PEG) to maintain nutrition and hydration is recommended prior to the onset of respiratory symptoms due to a potential increase in respiratory complications with later insertion ${ }^{9}$. However, as PEG tubes offer little or no extension of life, have minimal effect on relieving aspiration and can be uncomfortable, some people with MND refuse PEGs ${ }^{11}$.

The seminal clinical care resource for diagnosis and care of people with MND is the evidence-based guidance published by the UK National Institute for Health and Care Excellence (NICE) in 2016. These guidelines provide clear recommendations for recognition of the disease, referral to specialist services, how information and support should be provided at diagnosis, determining cognitive capacity, care planning care that takes account of various prognostic factors as well as psychological and social care needs, how care should be organised, end of life planning, and symptom management (including key points to include in PEG and NIV-related conversations). Early discussion of the implications, benefits and burdens of both NIV and PEG tubes is recommended in this and other international consensus evidence-based guidelines ${ }^{9,12}$, however the extent to which this guidance has translated into practice is underreported ${ }^{13}$.

Research into the experiences of people with MND and their families frequently suggests that clinician communication is generally inadequate, particularly when delivering the diagnosis ${ }^{14-16}$. For people with MND, deteriorating health and increasing symptoms mean that treatment decisions involving potential life-sustaining technologies are often faced early in the person's clinical care. Thus, accurate information about the benefits and burdens 
as well as the life extension limitations of such treatments needs to be communicated early and revisited as the disease progresses ${ }^{9}$. A potential complication lies in how MND is perceived and characterised by clinicians. The variants of MND and the sometimes unpredictable timing of progression of the disease can mean that the point at which a person is perceived as having a chronic and terminal disease becomes difficult to predict. The point at which chronic illness becomes defined as terminal may confuse the timing of support required by the person with MND and their caregivers ${ }^{17}$. In addition, multiple health professionals and several different service organisations may be involved with the person with MND from diagnosis, which has the potential for missed communications, confusion and conflicting messages.

The problem this study thus sought to address was that it is unknown whether clinicians implement best evidence-based guidance in their communications about end-of-life treatment choices with people with MND and their family members. The objectives of the study were to describe clinician communication surrounding NIV including end-of-life choices, to understand how clinicians check the level of understanding among patients and family members of the benefits, burdens and potential of NIV withdrawal prior to NIV commencement, and to compare the content, process and outcomes of NIV communication as described by clinicians and families of people with MND within this study against the currently available recommendations relating to commencement and withdrawal of NIV and related end-of-life care options. To that end, the overarching research question we sought to answer was 'How effective are clinicians' efforts in facilitating patients' and family members' understanding of the options regarding PEG and NIV, and of the value and possible burdens of those treatments?

\section{Methods}

Design. This study was conducted using Interpretive Description (ID) methodology ${ }^{18,19}$. ID was developed principally as a process for obtaining knowledge within the context of clinical events to elicit change ${ }^{9}$ and incorporates aspects from grounded theory and ethnomethodology in its approach to purposive data collection ${ }^{10}$. The ID process and outcome enables light to be thrown on a collection of expressed truths to inform a practical change, and for this reason it was selected as the most appropriate approach for investigating communication between clinicians, patients and family members. The purpose of the study was to answer the following research question: 'How effective are clinicians' efforts in facilitating patients' and family members' understanding of the options regarding PEG and NIV, and of the value and dis-benefits of those treatments?' and to address there related objectives (to describe clinician communication surrounding NIV including end-of-life choices, to understand how clinicians check the level of understanding among patients and family members of the benefits, burdens and potential of NIV withdrawal prior to NIV commencement, and to compare the content, process and outcomes of NIV communication as described by clinicians and families of people with MND within this study against the currently available recommendations relating to commencement and withdrawal of NIV and related end-of-life care options).

\section{Setting}

The study was set in two Australian states: Western Australia and New South Wales.

\section{Sample}


Purposeful sampling ${ }^{18}$ was employed to ensure the participation of informants with knowledge of the phenomenon of interest. The sample included healthcare clinicians involved with the respiratory care of MND, NIV initiation, NIV withdrawal and end-of-life care, and relatives of deceased people with MND who had used NIV. Uninvited, one person with MND who was using NIV requested inclusion in order to share experiences. Therefore, one interview was conducted with a person with MND. These data were used to illuminate and contextualise the two primary data sets.

Additional participant characteristics are provided in Tables 1 and 2.

Table 1. Family Participant Demographics

\begin{tabular}{|c|c|c|l|c|}
\hline $\begin{array}{c}\text { Family } \\
\text { Participants }\end{array}$ & $\begin{array}{l}\text { Health knowledge } \\
\text { and/or health } \\
\text { information from } \\
\text { internet }\end{array}$ & $\begin{array}{l}\text { Regional, rural } \\
\text { or remote }\end{array}$ & $\begin{array}{l}\text { Primary clinical } \\
\text { responsibility } \\
\text { for overall care }\end{array}$ & $\begin{array}{l}\text { Part of } \\
\text { structured MDT }\end{array}$ \\
\hline F 1/2 & No & Regional/rural & $\begin{array}{l}\text { Unclear: GP and } \\
\text { neurologist }\end{array}$ & No \\
\hline F 3 & Yes & Regional & $\begin{array}{l}\text { Neurologist and } \\
\text { GP }\end{array}$ & Yes \\
\hline F 4 & No & Rural & GP & No \\
\hline F 5 & Yes & Remote & GP & No \\
\hline F 6 & Yes & Rural & GP & No \\
\hline P 1 & No & Regional & Neurologist & Intermittently \\
\hline
\end{tabular}

Note: General Practitioner (GP), Multidisciplinary team (MDT)

Table 2. Clinician Participant Demographics 


\begin{tabular}{|c|c|c|c|c|}
\hline Clinician & Specialty & $\begin{array}{l}\text { Years }(\mathrm{y}) \text { of MND experience } \\
\text { and \% of workload dedicated } \\
\text { to caring for people with } \\
\text { MND }\end{array}$ & $\begin{array}{l}\text { Involved with } \\
\text { NIV withdrawal } \\
\text { discussions }\end{array}$ & $\begin{array}{l}\text { Regional, rural } \\
\text { or remote }\end{array}$ \\
\hline C1 & $\begin{array}{l}\text { Palliative Care } \\
\text { Consultant (Medical } \\
\text { Practitioner) }\end{array}$ & $\begin{array}{l}10+y \\
\text { Varies }\end{array}$ & Yes & $\begin{array}{l}\text { Regional and } \\
\text { rural }\end{array}$ \\
\hline C2 & $\begin{array}{l}\text { Palliative Care Specialist } \\
\text { (Medical Practitioner) }\end{array}$ & $\begin{array}{l}10 y \\
\text { Varies }\end{array}$ & Yes & Regional \\
\hline C3 & $\begin{array}{l}\text { Palliative Care Specialist } \\
\text { (Medical Practitioner) }\end{array}$ & $\begin{array}{l}17 y \\
\text { Varies }\end{array}$ & Yes & Regional \\
\hline C4 & $\begin{array}{l}\text { Respiratory Specialist } \\
\text { (Medical Practitioner) }\end{array}$ & $\begin{array}{l}12 \text { y } \\
\text { Varies }\end{array}$ & Sometimes & $\begin{array}{l}\text { Regional and } \\
\text { rural }\end{array}$ \\
\hline C5 & $\begin{array}{l}\text { Respiratory Specialist } \\
\text { (Medical Practitioner) }\end{array}$ & $\begin{array}{l}6 y \\
75 \%\end{array}$ & Yes & $\begin{array}{l}\text { Regional and } \\
\text { rural }\end{array}$ \\
\hline C6 & Neurological Nurse & $\begin{array}{l}4.5 \mathrm{y} \\
\text { Intermittent }\end{array}$ & No & $\begin{array}{l}\text { Regional and } \\
\text { rural }\end{array}$ \\
\hline C7 & Neurological Nurse & $\begin{array}{l}8 \mathrm{y} \\
\text { Intermittent }\end{array}$ & $\begin{array}{l}\text { Indirectly; when } \\
\text { patient requires } \\
\text { information }\end{array}$ & $\begin{array}{l}\text { Regional and } \\
\text { rural }\end{array}$ \\
\hline C8 & Palliative Care Nurse & $\begin{array}{l}16 \mathrm{y} \\
\text { Intermittent }\end{array}$ & Yes & Regional \\
\hline C9 & Palliative Care Nurse & $\begin{array}{l}14 \mathrm{y} \\
\text { Intermittent }\end{array}$ & Yes & Regional \\
\hline C10 & Palliative Care Nurse & $\begin{array}{l}5 \mathrm{y} \\
\text { Intermittent }\end{array}$ & Yes & $\begin{array}{l}\text { Regional and } \\
\text { rural }\end{array}$ \\
\hline C11 & $\begin{array}{l}\text { Respiratory Specialist } \\
\text { (Medical Practitioner) }\end{array}$ & $10 y$ & Yes & $\begin{array}{l}\text { Regional and } \\
\text { rural }\end{array}$ \\
\hline C12 & Physiotherapist & $5 \%$ of annual work & Yes & Regional \\
\hline C13 & Social Worker & approx. 30 MND pts ongoing & Sometimes & Regional \\
\hline C14 & $\begin{array}{l}\text { MND Clinical Nurse } \\
\text { Specialist }\end{array}$ & $\begin{array}{l}14 \mathrm{y} \\
\text { Ongoing }\end{array}$ & Yes & Regional \\
\hline C15 & $\begin{array}{l}\text { Gastroenterologist } \\
\text { (Medical Practitioner) }\end{array}$ & $\begin{array}{l}\text { Sees 2-4 people with MND } \\
\text { monthly }\end{array}$ & No & Regional \\
\hline C16 & $\begin{array}{l}\text { MND Clinical Nurse } \\
\text { Consultant }\end{array}$ & $\begin{array}{l}15 \mathrm{y} \\
\text { Ongoing }\end{array}$ & Yes & Regional \\
\hline C17 & $\begin{array}{l}\text { Respiratory Clinical } \\
\text { Nurse Consultant }\end{array}$ & $\begin{array}{l}22 \text { y } \\
\text { Varies }\end{array}$ & Yes & Regional \\
\hline C18 & $\begin{array}{l}\text { Rehabilitation MND } \\
\text { Specialist (Medical } \\
\text { Practitioner) }\end{array}$ & $\begin{array}{l}16 \text { y } \\
\text { approx. } 30 \text { MND/year }\end{array}$ & No & Regional \\
\hline C19 & $\begin{array}{l}\text { Palliative Care } \\
\text { Consultant (Medical } \\
\text { Practitioner) }\end{array}$ & $\begin{array}{l}11 \text { y } \\
\text { approx. } 30 \text { MND/year }\end{array}$ & Yes & Regional \\
\hline
\end{tabular}

\section{Participant recruitment}


Clinician and family participants with experience of MND care were invited to participate through palliative care services, hospitals, support organisations and specialist palliative centres care via email, letter, newsletter or face-to-face invitation by staff members. An information sheet and consent form were sent to those who expressed interest. All participants who requested the information sheet subsequently agreed to be interviewed. No participant who consented to be interviewed later withdrew.

\section{Data collection}

Data were obtained through single audio-recorded one-to-one semi-structured interviews with individuals that were conducted by [the first author], who is both a senior palliative care nurse and researcher with extensive training and experience in interviewing, communication and information gathering. All clinician interviews took place in a private room within their workplace or via videoconference or telephone. All family participants chose home interviews. No family participant was known to the interviewer prior to recruitment into the study.

Clinician participants were asked open-ended questions about what/when they communicated to people with MND and their families about NIV, its limitations, its benefits and its burdens. They were asked how they communicated the withdrawal of NIV, early palliative care referral, end-of-life choices, Advance Health Directives (AHD) and PEGs. Further, clinicians were asked how they ascertained understanding of the information by the person with MND and their families.

Family member participants and the person with MND were asked to consider two points in time: first when respiratory symptoms commenced and second when it became necessary to consider end-of-life care options. They were asked what they recalled at each time-point about the communication about PEG and NIV, and NIV withdrawal. They were also asked what they understood about the need for early palliative care referral, benefits and possible burdens of NIV and PEGs and whether AHDs were encouraged by clinicians.

All interviews were terminated when the participant indicated they had nothing further to add, and each participant received a copy of their transcribed interview and all approved its inclusion in data analysis ${ }^{20}$. Data collection ceased when saturation of themes was achieved.

\section{Data analysis}

Participant de-identification by the principal investigator occurred prior to the interview transcription, through a pseudonym allocation (e.g. P1). The initial phase of the data analysis identified emergent words and phrases ('codes') that related to the research questions. The NVivo $11^{\mathrm{TM}}$ software package was used to assist the process of coding the developing sub-themes and themes (Figure 1). When no new data were provided, saturation was assumed, and no further interviews occurred. 
Figure 1. Example of the Coding Tree

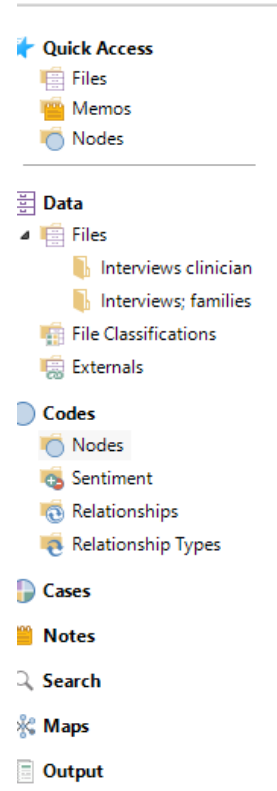

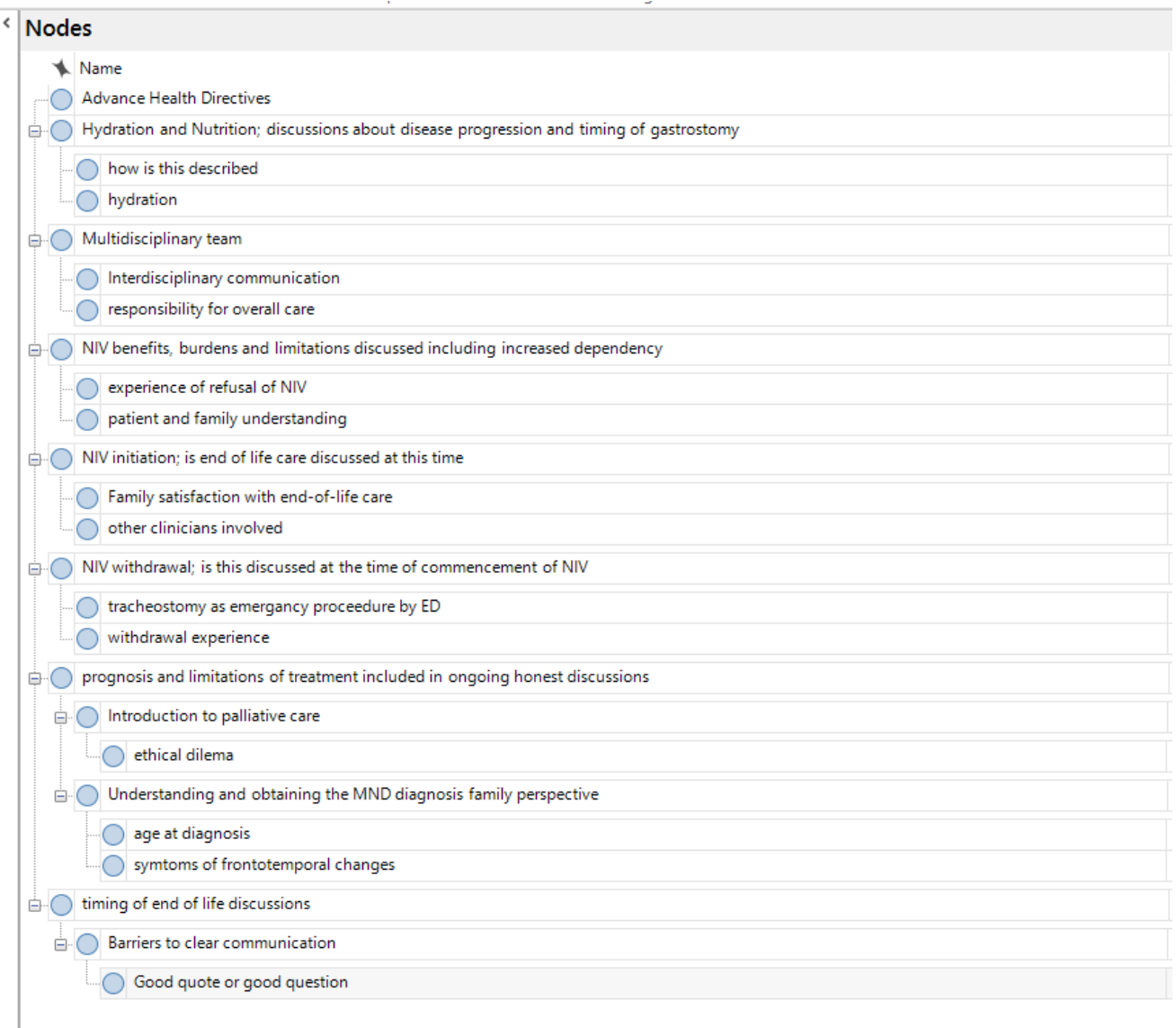

\section{Trustworthiness}

Trustworthiness of the research was assured primarily by designing interview questions which encouraged participants to describe conversations they had with clinicians surrounding the initiation, use and ultimate removal of NIV in patients with MND ${ }^{20}$. Several additional measures were implemented to ensure trustworthiness of the study. First, the transcribed interviews were returned to the participants for validation and approval for use in the data analysis ${ }^{20-22}$. Second, all interviews were analysed by the first author, and three were also analysed independently by author two; similar themes were derived by both. Third, themes developed from analysis were discussed by all members of the research team and consensus reached. Fourth, an audit trail that includes interview transcripts, analysis of data, process notes, notes about difficulties encountered, personal notes and draft documents have been kept ${ }^{21-23}$.

\section{Ethical considerations}

Approval to conduct the study was obtained from the Human Research Ethics Committees at Edith Cowan University (ECUHREC Number 12099), Silver Chain Hospice 
Nursing WA, two St John of God Hospital sites in WA and the Neurological Council of WA. Participants were offered the opportunity to ask questions and informed of their right to withdraw at any time until data analysis. Information on counselling services was provided in case of distress following the discussion. Participants who agreed to be interviewed and audio-recorded signed a consent form.

\section{Results}

Nineteen clinician participants were interviewed, eight of whom had experience of early respiratory symptoms in people with MND and ten of palliative or end-of-life care. Six family member participants and one person with MND were interviewed, all from Western Australia. Twenty nine hours and thirty minutes of data were collected from which six major themes emerged when data analysed: 'Experience of clinicians with NIV withdrawal'; 'Timing and content of communication about the benefits and burdens of NIV, PEGs and end-of-life choices'; 'Time allocated for communicating and discussing end-of-life choices'; 'Early referral to palliative care and family understanding of palliative care'; 'Communication within a multi-disciplinary team'; and 'Patient and family communication and understanding'.

\section{Experience of clinicians with NIV withdrawal}

All the clinician participants interviewed had many years of experience of communicating with patients and relatives about end-of-life decisions (4.5-22 years), with 12 of the 19 clinicians having had at least 10 years in practice. Significant practice experience did not appear to make discussions about NIV withdrawal easier or more likely for clinician participants, and despite their knowledge of the best practice evidence, many clinicians reported difficulty giving 'good' information when there was uncertainty about the deterioration trajectory.

The complex challenges of deciding the exact protocol and timing for NIV withdrawal, assessing family readiness for the information and maintaining comfort until death, were described by several clinicians as particularly dreaded. Participant C11, a medical practitioner specialising in respiratory care, exemplified this in the following quote:

[it's] bloody awful, because - the when, how, pharmacotherapy, you know. What do you do? Do you necessarily withdraw NIV or do you let people die on NIV? ... [And] I suspect it's enormously difficult from the family's point of view unless the conversations leading up to it have been really good and really clear.

C19 (palliative care consultant): I think one of the barriers is sensitivity or worrying that that's - even having that conversation is going to upset the patient or the family.

One of the most noted barriers clinician participants experienced in this regard was patient denial:

C4 (respiratory specialist): [Often you hear] "Oh, I just don't want to think about it. I don't want to know." So that can be a bit of a challenge that their defence mechanism, their way of coping is one of, "That's later on," denial.

Family members' experiences of this uncertainty and vagueness in clinicians about withdrawal of NIV meant that they then didn't have enough information to contribute an 
opinion about care decisions. F5, who self-reported as having high health literacy and knowing what questions to ask, said:

Because in these appointments you - particularly with a neurologist who gives you an overall reading on how the whole thing's going, if you don't ask questions, and you're not an assertive sort of person, sometimes I think you could walk out missing a lot, do you know what I mean?

In some cases, no-one ever discussed NIV withdrawal with patients and families, and the impact of this can have profoundly devastating and long-lasting effects:

F1 (family): I think now, I would have opted for [NIV withdrawal] because Mum was so uncomfortable and so suffering that I would have opted to say, "Let's, you know, ditch that..." - and I think now Dad would have taken that option. But from what we knew, and what we while we were going through it, I don't think we would have done any different to what we did do. But do you know what I mean, hindsight's a wonderful thing ...

I regret - and you can use that as a quote if you want - but I regret the last three nights that mum had at home. It was awful for her, for dad, for me. It was just - still burned in my memory, and it's hard to sort of go away.'

\section{Timing and content of communication about the benefits and burdens of NIV, PEGs and end-of-life choices}

Many of the clinician participants reported that the timing for raising the topic of the end of life and NIV withdrawal with patients and family members challenging. There was also confusion among clinicians about who was responsible for these communications, and concern that patients might not be prepared for them. Most of the specialist clinicians interviewed said they tried to ascertain how much the person with MND and their family knew about the course of the disease and tailored the communication content accordingly.

C4 (respiratory specialist): I mean, you're talking about end-of-life issues, which many health practitioners are uncomfortable talking about. And then I would think 20 to 40 to 50 per cent of patients will tend to say, "Well, we don't want to talk about that. We'll think about it when the time comes." So even though you may have the best intentions of trying to have all this out in the open and discussed and documented, it's not always the case that the patients wish to discuss it.

C2 (palliative care specialist): We're palliative care doctors. We like to think that we're good at communicating, but I think, I acknowledge, that often families need to hear things multiple times.

Further, most clinician interviewees spoke about being sensitive to the contradictory nature of the complex information relating to withdrawal of NIV and what this means to patients and families:

C12 (physiotherapist): You're offering them something that potentially may treat their symptoms, but then at the same time saying, "Oh, by the way, you know, let's also talk about, you know, end of life as well."

C19 (palliative care consultant): I guess the pros is a very transparent discussion, isn't it, that you're actually, at the time of putting the - sorry, of starting the machine, the NIV, you're also talking about the possibility of withdrawal. I can see the merit of that. I guess on the 
other hand - I'm just thinking of the emotional dimension of that, and I guess that may - I'd have to think of the sensitivity of that conversation at that time.

C14 (MND clinical nurse specialist): It's a conversation that we dread, I think, to remove it, because the breathing is so essential to stay alive. And there's no good or there's no best timing for it.

Compounding clinicians' uncertainty about the right time for these discussions, many recognise the preservation of hope can underlie a family's wish to avoid discussing the end of life. The following describes the experience of how one clinician dealt with it:

F3 (family): And then when [the person with MND] was, you know, eventually diagnosed, we - by that stage we'd been reading up on best practice and, you know, we knew all about the multi-disciplinary team approach, etcetera. And [the health care professional's] response was, "Oh, you're not going to need [end of life care] for a long, long time. And don't talk to [patient and carer support organisation] - they're way too negative. I'll see you in a year."

\section{Time allocated for communicating and discussing end-of-life choices}

Insufficient time for these conversations was reported by the majority of the clinicians interviewed for a range of reasons, as participant C2 (palliative care consultant) said:

Time, you know. We're all very time poor, and these conversations take time, need to be revisited, the patient's cognitive ability, family issues. You know, conflict within a family. All sorts of things come into play.

Participant C13 (social worker) elaborated further on the complicating issue of patients' deteriorating cognitive ability:

What concerns me sometimes with that [frontotemporal dementia] is that they [person with $M N D$ ] don't have a deeper understanding of the situation [as they would] if they didn't have the FT [frontotemporal] [issues] happening, and it impacts on the carers, and that's my concern

With limited time for communication, clinicians described prioritising explanations about NIVrelated technicalities.

C11 (respiratory specialist): [I focus on] how to set up the mask, how to set up the machine, how to plug it in, what to do if it leaks, what to do if they get rain out, what to do if they get this, that and something else... a lot of the attention can be focused on the sort of practicality of the machine, and the sort of softer, more difficult conversations often get a little bit left to the side.

The potential impact of this on patients and families, was that they may not have meaningful input to care:

F6 (family): So, you know, some health professionals - I think periods of silence to listen to the client are needed without the health professional thinking, "I've got to tell them $X, Y$, Z...”."

Patient and/or family member reluctance or lack of readiness to 'go there' was also cited by clinical respondents as a barrier to having these conversations:

C11 (respiratory specialist): There are some people that are willing to engage in this, and then there are other people where you can't get them to engage in discussions about end-of- 
life care. And so, my goal is to do it early and to do it often until I feel like the patient and I, and family and $I$, are on the same page. But it's sometimes, in the real practical world, more difficult than that.

\section{Early referral to palliative care and family understanding of palliative care}

Many clinicians are reluctant to make or accept an early referral for people with MND to palliative care despite acknowledging this to be best practice, and sometimes the referral is declined by patients and/or family members.

C4 (respiratory specialist): ...ideally [I refer] all patients very early on, close to the time of diagnosis. For various reasons some patients don't want that.

C2 (palliative care consultant): To be honest, most of my [MND] patients are referred very late, and we look after them for their end-of-life care.

C16 (MND nurse consultant): ...some pall. care teams are quite open to that [early intervention], but some pall. care teams have this weird definition period that they will not accept the patient until they have three months or less to live.

F5 (family): She's a specialist. And she said, "Now, I've got a letter here from your GP saying that you're in denial about all this." And we said, "We're definitely not in denial about what's happening to us. We're just in denial that we need to see a palliative care team so early. That word 'palliative' over-shone whatever they were saying to us"

F3 (family): [Palliative care] was discussed, and because ... we now know that palliative care is really the only thing that you can do with motor neurone disease...but at that stage we were thinking "end of life"?? ... and we were getting a bit paranoid.

\section{Communication within a multi-disciplinary team}

Despite the recommendation that a multi-disciplinary team (MDT) approach is used, poor experiences of this were evident.

C1 (palliative care consultant): I think my ...fear is you can get so many teams of people involved. You've got specialist palliative care, GP and primary care, respiratory care, gastroenterologist who's been involved with the PEG, the rehabilitation team, a neurologist who's saying - you know, and the possibilities of confusion and misinformation are enormous... I was going to say warfare [can occur].

Further, the health professionals interviewed described suboptimal communication between professionals:

C4 (respiratory specialist): Look, I don't think [communication between healthcare professionals is] particularly ideal at all. The communication we have is by letter, very occasionally a phone call. I don't get a lot of - I mean, I write letters [to other clinicians], and I think I'm communicating, but I don't feel I get a lot of feedback, unless there's a big problem.

In some cases, this was because there was no MDT: 
C19 (palliative care consultant): Now, the interesting thing in the city is that not everywhere has a multi-disciplinary team. So, it's a bit of a patchwork quilt, and indeed would be the whole of Australia a patchwork quilt.

Gaps in communication within MDTs were found to be confusing for patients and families who needed to repeat the same information:

F1 (family): We'd been to a few speechies [speech therapist] and dietitians, which Dad was getting confused about. So, I sort of explained to them that the dietitian was about the nutrients; the speechy was about ... how to swallow, and the muscles in the neck. And Dad said, "We're saying the same things to the same people."

\section{Patient and family understanding}

Denial and lack of understanding by some people with MND and their families about how quickly the disease can progress was expressed as a communication barrier by some clinician participants. Others noted that some people with MND and their families had been given little or conflicting information about the disease prior to seeing them.

C2 (palliative care consultant): Some of them have clearly been told but don't necessarily want to hear, understand or acknowledge, and some clearly have [had] very limited explanation.

C1 (palliative care consultant): There was one person who was told it [MND] would - he'd known patients where it had burnt out after a few years and not progressed. So those patients - you know, it can be difficult because they may get mixed messages - different messages when they see a neurologist in a clinic who says, "Oh, you shouldn't be thinking about a gastrostomy" when we're already starting to talk about gastrostomy.

Several of the health professionals in our study put forward that advice to people with MND regarding PEGs was unclear.

C3 (palliative care specialist): Just touching on PEG tubes again, I think they're often sold to people as more of a solution than they are, and I don't think the difficulties of PEG tubes are adequately communicated... So, I think, you know, they're kind of seen as an easy option when someone can't swallow, and the reality of dealing with the other side of it isn't always discussed as well.

As with NIV, some clinician participants felt the decision about PEG tube insertion required a degree of understanding that some patients and families did not have:

C15 (gastroenterologist): Understanding the medical complexities of PEG tube insertion needs a fair degree of health literacy and that can sometimes be a barrier.

\section{Discussion}

This study sought to answer one overarching research question and fulfil three objectives, and those aims were achieved. Four key learnings emerged from this study. The first was that neither extensive practice experience nor knowledge of best practice evidence appear to make discussions about NIV withdrawal with people with MND and their families 
easier or more likely for clinicians. The second was that knowing when the time is right to raise the topic of the end of life and NIV withdrawal with people with MND and family members is challenging for clinicians and once clinicians do commit to broaching these subjects, having adequate time for these very sensitive conversations is difficult to find. The third was that knowing who is responsible for initiating and continuing the conversation is not well understood by clinicians. Fourth was that family participants reported, likely as a result of all of the above, that they and their relatives with MND found clinicians' communication on these topics to be inadequate. This led families to 'top up' their knowledge from less authoritative sources. The family participants in this study admitted to seeking clarifying information from the internet.

Clinician avoidance of difficult discussions seen in this research has been previously identified in MND ${ }^{9}, 13,16,24-26$. International guidelines recommend early involvement of specialist palliative care and communication of end-of-life options ${ }^{9,12}$. This study has found clinicians make efforts to deliver end-of-life options, but not necessarily as the guidelines recommend ${ }^{9,12}$. The assumption that people will turn to the Internet to address their questions and fears may lessen the urgency clinicians feel to initiate such sensitive communication.

The clinicians stated that time limitations affected their ability to comprehensively communicate the progressive nature of MND, the issues related to NIV and PEGs, treatment and end-of-life choices. It also limited their ability to ensure patient understanding of potential NIV withdrawal. Whilst all the bereaved families recognised the variability of the disease progression, all wished an idea of remaining life expectancy could have be given at symptom onset to enable some life planning ${ }^{27,28}$. The proposal to initiate NIV is an accepted trigger point at which clear discussion should occur. These discussions are often delayed by clinicians' perception of a lack of patient or family readiness to engage in them and clinicians may not acknowledge the necessity of these discussions when the patient's condition deteriorates ${ }^{29}$. Most of the clinicians in this research focussed on the positives surrounding symptom control rather than prolonging suffering by surviving longer.

Although the most recent guidelines recommend referral to palliative care soon after diagnosis, this study found that in practice this did not usually occur, agreeing with an extensive systematic review ${ }^{13}$. Both clinician and family participants agreed that determining the optimal time for referral to a palliative care service is complex ${ }^{16,30,31}$. The palliative care specialists stated that they often had to clearly point out and belatedly discuss end-of-life options not discussed earlier 14, 27,32, 33. Whilst some clinicians had minimal knowledge of the MND guidelines, others stated that the recommendations relating to early end-of-life communication were emotionally inappropriate. The bereaved families stated that early referral to a palliative care service was overwhelming, equating palliative with death, and it was apparent that the capabilities of palliative care had not been communicated or understood. Early symptom control communication enables patients and families time for informed discussion, to plan and prepare, and may prevent unwanted symptom control interventions such as NIV, gastrostomy tubes and the potential of invasive ventilation. Other studies tend to support these conclusions ${ }^{31,34}$. Several studies show that people with MND would like as much information as is available and the opportunity to discuss treatment options, believing that doctors should initiate such conversations ${ }^{35,36}$. 
Anecdotally, experience with communicating end-of-life choices to palliative care patients generally enhances a clinician's ability to sensitively discuss options of care ${ }^{36}$. Clinical experience in palliative care and respiratory medicine was, therefore, anticipated to facilitate the difficult discussions soon after diagnosis. In this study, however, the experience of having prior involvement with withdrawal of NIV, an important aspect of MND, did not always make such communication easier for the clinicians ${ }^{37}$.

The provision of structured multidisciplinary teams (MDT) was patchy within the area studied. Families and clinicians identified that communication barriers were pronounced when there is no structured MDT or single health professional responsible for patient care. Families with poor health literacy or knowledge of the health care systems lacked the skills or confidence to ask relevant questions relating to end-of-life and symptom control choices. The families and people with MND were aware time was not on their side and resented intrusion from many services and considered repetition of information to multiple people within an MDT as time-consuming, fatiguing and overwhelming ${ }^{25,38}$.

Prolonging life and hope were considered important to the clinicians and influenced their decisions to discuss NIV withdrawal and end-of-life choices. None of the bereaved family participants recalled discussion about the potential of prolonging life in the context of possible suffering ${ }^{32,39,40}$. Reflecting, some bereaved family participants said that their family member did suffer from not understanding that the NIV could be withdrawn.

There are limitations to this study, including only one perspective of people with MND was included. Nonetheless, our questions about how communication about PEG and NIV is delivered as recommended by guidelines, how effective clinicians' efforts are in facilitating patients' and family members' understanding of PEG and NIV, and of the value and disbenefits of those treatments were answered to some degree: we discovered that communications around end-of-life care options per se, and PEG and NIV in particular, are complicated by myriad of considerations and challenges that are not accounted for in the evidence-based guidance.

How effective are clinicians' efforts in facilitating patients' and family members' understanding of the options regarding PEG and NIV, and of the value and possible burdens of those treatments? This research found the clinician preference for preservation of hope, lack of time for in-depth communication and the stigma of palliative care were all barriers to family understanding. The results will be of interest to all health care clinicians involved in the care of those diagnosed with a life-limiting disease for whom respiratory support may be helpful and their families, and to policy makers. The relevance of the study findings for patients and for carers is that the health service user perspectives reported can be used to inform practice improvements and further research, which is warranted to effectively capture the barriers to effective, timely and comprehensive end of life treatment options. Recent endof-life and clinical palliative care literature suggests that NIV is being increasingly employed as a palliating intervention for dyspnoea beyond MND to other progressive respiratory diseases such as lung cancer and emphysema ${ }^{41}$. Understanding the gaps in communication, when discussions occur, how well the necessary information is communicated and comprehended by people with MND and their families is, therefore, becoming increasingly relevant to other diseases ${ }^{41,42}$. The views of clinicians working with patients with chronic obstructive pulmonary disease and interstitial lung disease have been recently published and this adds the views of those providing MND care ${ }^{43}$. 


\section{Ethics approval}

The Human Research Ethics Committee at Edith Cowan University (ECUHREC: Number 12099) approved commencement of participant interviews in June 2015. Subsequently, ethics approvals were sought from Silver Chain Hospice Nursing, St John of God Hospital Bunbury and Murdoch, WA and the Neurological Council of WA and granted in mid-2015.

\section{Acknowledgements}

This research could not have occurred without the generous time given by the clinicians, the bereaved participants and the one person with MND who participated in this study.

I would like to sincerely thank Prof. Anne Wilkinson without whose support and knowledge this research would not have been completed.

\section{Funding}

This author(s)received no financial support for the research, authorship and/or publication of this article.

The author declares that there is no conflict of interest.

\section{References}

1. Borasio G, Voltz R and Miller R. Palliative care in amyotrophic lateral sclerosis in palliative care. Journal of Clinical Neurology 2001; 19: 829-847. 
2. Gent C. Understanding motor neurone disease. Nursing \& Residential Care 2012; 14: 646649. DOI: 2011793616.

3. Motor Neurone Disease Australia. MND care: palliative approach, http://www.mndcare.net.au/MND Care/PDF/Pages/3261 Palliative\%20approach 20141216044954 .pdf (2014, accessed 20/01/2015).

4. Longinetti $E$ and Fang F. Epidemiology of amyotrophic lateral sclerosis: an update of recent literature. Current opinion in neurology 2019; 32: 771-776. DOI: 10.1097/WCO.0000000000000730. 5. Doyle D, Hanks G, Cherny N, et al. Oxford textbook of palliative medicine. $3^{\text {rd }}$ ed. New York: Oxford University Press, 2005.

6. Phukan J and Hardiman O. The management of amyotrophic lateral sclerosis. Journal of Neurology 2009; 256: 176-186. DOI: 10.1007/s00415-009-0142-9.

7. Chiò A, Logroscino G, Traynor BJ, et al. Global epidemiology of amyotrophic lateral sclerosis: A systematic review of the published literature. Neuroepidemiology 2013; 41: 118-130.

8. Motor Neurone Disease Australia. Facts and figures. https://www.mndaust.asn.au/Getinformed/What-is-MND/Facts-and-figures.aspx (2019, accessed 5/5/2020).

9. National clinical guidelinecCentre (UK). Motor neurone disease: Assessment and management. (NICE Guideline, No. 42.)

10. Bourke S, O'Neill C, Williams T, et al. The changing landscape of non-invasive ventilation in amyotrophic lateral sclerosis. Journal of Neurology Neurosurgery Psychiatry 83,

http://.jnnp.bmi.com/content/83/4/368. (2012, accessed 26 March 2013).

11. ProGas Study Group. Gastrostomy in patients with amyotrophic lateral sclerosis (ProGas): A prospective cohort study. The Lancet Neurology 2015; 14: 702 - 709. DOI: 10.1016/S14744422(15)00104-0.

12. Andersen $P, A$ abrahams $S$, Borasio $G$, et al. EFNS guidelines on the clinical management of amyotrophic lateral sclerosis (MALS)-revised report of an EFNS task force. European Journal of Neurology 2012; 19: 360-375. 2011/09/15. DOI: 10.1111/j.1468-1331.2011.03501.x.

13. Flemming K, Turner V, Bolsher S, et al. The experiences of, and need for, palliative care for people with motor neurone disease and their informal caregivers: A qualitative systematic review. Palliative medicine 2020; 34: 708-730. DOI: 10.1177/0269216320908775.

14. Aoun S, Connors S, Priddis L, et al. Motor neurone disease family carers' experiences of caring, palliative care and bereavement: An exploratory qualitative study. Palliative Medicine 26(6), http://ecu.summon.serialssolutions.com/2.0.0/link/0/ (2012, accessed 20/3/17).

15. Belkora J. Use of the decision process for improving the quality of medical decisions. In: Royal Australian College of General Practitioners [combined conference]: Health Informatics Society of Australia (eds Coiera E, Chu S and Simpson C), Brunswick East, Victoria, 2003, pp.385-397.

16. Faull $C$, Rowe-Haynes $C$ and Oliver $D$. Issues for palliative medicine doctors surrounding the withdrawal of non-invasive ventilation at the request of a patient with motor neurone disease: $\mathrm{A}$ scoping study. British Medical Journal Support \& Palliative Care 2014; 4: 43-49. 2014/03/20. DOI: 10.1136/bmjspcare-2013-000470.

17. Lerum S, Solbrække K and Frich J. Family caregivers' accounts of caring for a family member with motor neurone disease in Norway: A qualitative study. BMC Palliative Care 2016; 15: 22. DOI: 10.1186/s12904-016-0097-4.

18. Thorne S, Reimer Kirkham S and MacDonald-Emes J. Interpretive description: A noncategorical qualitative alternative for developing nursing knowledge. Research in Nursing \& Health 1997; 20: 169-177. DOI: 10.1002/(SICI)1098-240X(199704)20:2<169::AID-NUR9>3.0.CO;2-I. 19. Thorne S, Reimer Kirkham S and O'Flynn-Magee K. The analytic challenge in interpretive description. International Journal of Qualitative Methods 2004; 3: 1-11. DOI: $10.1177 / 160940690400300101$.

20. Streubert H and Carpenter D. Qualitative research in nursing. $5^{\text {th }}$ ed. Philadelphia: Lippicott, Williams \& Wilkins, 2011. 
21. Polit D, Beck C and Hungler B. Essentials of nursing research. $5^{\text {th }}$ ed. New York: Lippincott Williams and Wilkins 2001.

22. Pope C and Mays N. Qualitative research in health care. $3^{\text {rd }}$ ed. Oxford: Wiley Blackwell 2006.

23. Guba E and Lincoln Y. Competing paradigms in qualitative research. In: Denzin NK and Lincoln YS (eds) Handbook of qualitative research. Thousand Oaks, California: Sage, 1994.

24. Baxter S, Baird W, Thompson S, et al. The initiation of non-invasive ventilation for patients with motor neuron disease: Patient and carer perceptions of obstacles and outcomes. Amyotrophic Lateral Sclerosis and Frontotemporal Degeneration 2013; 14: 105-110. DOI: 10.3109/17482968.2012.719238.

25. Baxter S, Baird W, Thompson S, et al. The use of non-invasive ventilation at end of life in patients with motor neurone disease: A qualitative exploration of family carer and health professional experiences. Palliative Medicine 2013; 27: 516-523. DOI: 10.1177/0269216313478449. 26. Faull C, Phelps K, Regen E, et al. Withdrawal of NIV at the patient's request in mnd: Exploration of the issues related to communication. British Medical Journal Support \& Palliative Care 2014; 4: A25. 2014/03/20. DOI: 10.1136/bmjspcare-2014-000654.68.

27. Whitehead B, O'Brien MR, Jack BA, et al. Experiences of dying, death and bereavement in motor neurone disease: A qualitative study. Palliative Medicine 2012; 26: 368-378. DOI: 10.1177/0269216311410900.

28. Bentley B and O'Connor M. The End-of-Life Experiences of People with Motor Neurone Disease: Family Carers' Perspectives. Journal of Palliative Medicine 2016. DOI: 10.1089/jpm.2015.0538.

29. Mitsumoto $\mathrm{H}$ and Rabkin J. Palliative care for patients with amyotrophic lateral sclerosis: "Prepare for the worst and hope for the best". JAMA 2007; 298: 207-216. DOI: 10.1001/jama.298.2.207.

30. Boersma I, Miyasaki J, Kutner J, et al. Palliative care and neurology: Time for a paradigm shift. Neurology 2014; 83: 561-567. DOI: 10.1212/WNL.0000000000000674.

31. Dharmadasa T, Matamala J and Kiernan M. Treatment approaches in motor neurone disease. Current Opinion in Neurology, https://www.ncbi.nlm.nih.gov/pubmed/27454577 (2016, accessed 13/8/2016).

32. Foley $\mathrm{G}$, Timonen $\mathrm{V}$ and Hardiman $\mathrm{O}$. Understanding psycho-social processes underpinning engagement with services in motor neurone disease: A qualitative study. Palliative Medicine 28(4), http://ezproxy.ecu.edu.au/login?url=http://search.proquest.com/docview/1508797415?accountid= $\underline{10675}$

(2014, accessed 1/4/ 2014).

33. Ray R, Brown J and Street A. Dying with motor neurone disease, what can we learn from family caregivers? Health Expectations 2014; 17: 466-476. DOI: 10.1111/j.1369-7625.2012.00773.x.

34. Connolly S, Galvin M and Hardiman O. End-of-life management in patients with amyotrophic lateral sclerosis. The Lancet Neurology 14(4),

http://ezproxy.ecu.edu.au/login?url=http://search.proquest.com/docview/1663676388?accountid= 10675 (2015, accessed Apr 2015).

35. Anderson E, Kuru T, Munroe C, et al. End-of-life decision making in 42 patients with amyotrophic lateral sclerosis. Respiratory Care. Daedalus Enterprises Incorporated., 2007.

36. Blackhall L. Amyotrophic lateral sclerosis and palliative care: Where we are and the road ahead. Muscle \& Nerve 2012; 4513 FEB 2012. DOI: 10.1002/mus.22305.

37. Gabbay J and May A. Evidence based guidelines or collectively constructed "mindlines?" Ethnographic study of knowledge management in primary care. British Medical Journal 2004; 329: 1013. DOI: $10.1136 / \mathrm{bmj} .329 .7473 .1013$.

38. O'Brien $M$, Whitehead B, Jack B, et al. Multidisciplinary team working in motor neurone disease: patient and family carer views. British Journal of Neuroscience Nursing 2011; 7: 580-585. 
39. Ando $\mathrm{H}$, Williams $\mathrm{C}$, Angus $\mathrm{R}$, et al. Why don't they accept non-invasive ventilation? Insight into the interpersonal perspectives of patients with motor neurone disease. British Journal of Health Psychology 2014. DOI: 10.1111/bjhp.12104.

40. Ando H, Chakrabarti B, Angus R, et al. Experience of long-term use of non-invasive ventilation in MND: an interpretative phenomenological analysis British Medical Journal Supportive Palliative Care 2014: 50-56. DOI: 10.1136/bmjspcare-2013-000494.

41. Gifford A. Non-invasive ventilation as a palliative measure. Current Opinion in Supportive \& Palliative Care 2014; 8: 218-224. DOI: 10.1097/SPC.0000000000000068.

42. Quill C and Quill T. Palliative Use of non-invasive ventilation: Navigating murky waters. Journal of Palliative Medicine 2014; 14: 657-661. DOI: 10.1089/jpm.2014.0010.

43. Sørensen AR, Marsaa K, Prior TS, et al. Attitude and Barriers in Palliative Care and Advance Care Planning in Nonmalignant Chronic Lung Disease: Results From a Danish National Survey. Journal of palliative care 2020: 082585972093601. DOI: 10.1177/0825859720936012. 